\title{
The Publicity of Meaning and the Perceptual Approach to Speech COMPREHENSION
}

Berit Brogaard

Abstract

The paper presents a number of empirical arguments for the perceptual view of speech comprehension. It then argues that a particular version of phenomenal dogmatism can confer immediate justification upon belief. In combination, these two views can bypass Davidsonian skepticism toward knowledge of meanings. The perceptual view alone, however, can bypass a variation on the Davidsonian argument. One reason Davidson thought meanings were not truly graspable was that he believed meanings were private (unlike behavior). But if the perceptual view of speech comprehension is correct, then meanings (or at least conveyed meanings) are public objects like other perceivable entities. Hence, there is no particular problem of language comprehension, even if meanings originate in "private" mental states.

\section{Introduction}

Consider the following two views of language comprehension:

Inferential view: We hear the sounds associated with a speaker's utterance and infer (likely unconsciously but not necessarily on a subpersonal level) what was said, drawing on our competence in the syntax and semantics of the language together with background information.

Perceptual view: Fluent speakers of a language have a non-inferential capacity to auditorily (or otherwise) perceive not just the sounds of speech but also what was said or conveyed by the speaker.

There are no doubt circumstances in which the inferential view of language comprehension is correct. Suppose upon your return from the mall I hear you say 'I just bought a new goat' (Balcerak-Jackson, manuscript). It perceptually seems to me that you just said that you bought a new goat. But I make the 
inference that since you went to the mall and hate goats, you could not possibly have said that you just bought a new goat. I conclude that I probably misheard what you said and that you actually said that you board a new coat.

An interesting question - the most central question of this paper - is whether there ever are situations where we perceive meanings without going through a rational inference process, as suggested by advocates of the perceptual view. Thinkers have been divided on this question (see e.g. Fricker, 2003 \& Brogaard, 2016 in favor \& O'Callaghan against). Those in favor of the perceptual view typically combine the view with a thesis about justification, viz. the thesis that when we hear a speaker's utterance, the experience confers some degree of justification on our beliefs about what was said in the absence of defeaters (Fricker, 2003; Brogaard, 20I6). So, in the absence of defeaters, we can come to know what was said merely on the basis of hearing the utterance.

In combination the two views, the perceptual view and the justificatory view, provides us with a plausible response to the skeptical argument that we cannot come to know what speakers say. In this paper, I will first define the perceptual view mostly on empirical grounds. I will then briefly consider some considerations for and against the epistemic component of the perceptual view. Finally, I will show how the combined perceptual and epistemic views can defeat Davidsonian skepticism, and that the perceptual view on its own can defeat a variation on the skeptical argument against knowledge of meaning.

\section{The Perceptual View}

On the perceptual view, speakers at least sometimes sensorily grasp meanings. Suppose again that upon returning from the mall, it appears to me that you tell me 'I bought a new goat'. On the basis of background information I can come to the conclusion that you said that you bought a new coat. However, this is not what it appears to me that you said. What appears to me is that you said is that you bought a new goat. Here the perceptual view implies that you sensorily grasp the meaning that you bought a new goat.

A couple of remarks are in order here. First, what is perceived is the apparent utterance meaning, not something more complex. If you say 'I bought a new coat' but it appears to be that you uttered 'I bought a new goat', then I perceive the utterance meaning that you bought a new goat. It is a different question altogether whether I also perceive that you said that you bought a new coat. I shall leave this question to one side here. 
It may be asked, however, what the difference is between perceiving that something is the case and perceiving meanings. Suppose you tell me that the tomato is red. What I perceive is the proposition that the tomato is red. But on the assumption that perception has content, this is also what I perceive if I look at a red tomato. So, what is the difference? The main difference, in my view, is the way the meaning or proposition represents the external environment. In the former case, it represents it in a testimonial way, in the latter it presents in a visual way. The manner of representation thus differs in the two cases (Chalmers, 2004). Now, if I form a belief on the basis of the experience of the utterance meaning, I don't come to believe that the tomato is red. Rather, what I come to believe is that you said that the tomato is red. So, there is an asymmetry between the content of experiences of utterance meanings and beliefs about utterance meanings based on those experiences.

Second, the utterance meaning perceived is what appears to be conveyed by the speaker. What is conveyed may be different from or add to the perceived semantic meaning of the utterance. If after you have left plates in the sink for several days your roommate loudly states 'the dishes are dirty', what is conveyed presumably is not just that the dishes are dirty but also that you should wash them. If you say 'I haven't had breakfast', what you convey is not the semantic meaning that you have not have breakfast (ever) but rather that you have not had breakfast that very morning. On my take on the perceptual view, what is perceived is the apparent conveyed meaning, not the semantic meaning (if we ever have knowledge of semantic meanings when the latter are not conveyed, these meanings are typically inferred).

This latter point provides a natural response to an objection people often raise to a main consideration in favor of the perceptual view, viz. the view that differences in phenomenology between listening to known and unknown languages is traceable to differences in semantic properties presented in auditory experience (Bayne, 2009; Siegel, 2005; Pettitt, 20IO; O'Callaghan, 20II; Reiland, 20I5a).

The objection turns on the observation that most words are highly polysemous (O'Callaghan, 2OII). Casey O'Callaghan (2OII) agrees that there is a difference in phenomenology between listening to speech in known and unknown languages, but he argues against the claim that the phenomenal contrast is best explained in terms of our auditory perception of meanings. The phenomenal contrast is better understood in terms of our ability to differentiate language-specific phonological properties of the known language. Although this hypothesis is consistent with the view that we can non-inferentially perceive the content of speech, this explanation of the phenomenal 
contrast between listening to known and unknown languages indicates that O'Callaghan would argue against the view that we can perceive meanings and have auditory sensory phenomenology associated with them.

In arguing against the hypothesis that the phenomenal contrast between listening to a known and an unknown language is best explained by the hypothesis that we can hear meanings, O'Callaghan brings up the case of homophones. Homophones are expressions that are pronounced the same way but differ in meaning. They include homonyms, which share a spelling, as in the case of 'bank' (financial institution) and 'bank' (river bank), and heterographs, which do not share a spelling but are nonetheless pronounced the same way, such as 'pole' and 'poll'. Two utterances of the homophones 'pole' and 'poll' involve acoustically identical sounds. When listening to those sounds, we do not detect any difference in phenomenal character, despite the potential difference in meaning.

This is the gist of O'Callaghan's case against the view that the phenomenal contrast between listening to known and unknown languages is best explained in terms of an auditory experience of meanings. When the argument is understood in this way, it does not establish the hypothesis that the phenomenal contrast is not best explained perceptually (cf. Reiland, 2015a). Procedural/ functional words, such as 'but', 'or', 'and' and 'not' can perform a multiplicity of functions in the language. For instance, the sentence 'Otavio is in his office, and he is writing' is true just in case both conjuncts are true. 'Otavio might be in his office, and he might be in Brazil', on the other hand, is true just in case one of the conjuncts is true. The general linguistic meaning of procedur$\mathrm{al} /$ functional words, such as 'but', 'or', 'and' and 'not' is normally inaccessible to consciousness. But so is the lexical meaning of descriptive words, such as 'chair', 'healthy' and 'door' because of the massive polysemy of ordinary language (Recanati, 2004). 'Chair', for instance, could mean (among many other things) a seat for one person, the head of a department or organization, and an office of position or authority (e.g. 'the new research chair of neuroscience'). Even if one could come up with some exhaustive disjunctive lexical entry specifying the multiple linguistic functions of procedural and descriptive words, it is implausible to think that we ordinarily comprehend speech by consciously accessing such complex lexical entries. If, however, linguistic meaning eludes consciousness, it can be neither perceived nor grasped.

What is accessible to consciousness is the utterance (or occasion) meaning of a particular use of a word. We have no trouble accessing the meaning of an utterance of the sentence 'The patient is healthy but she is still not eating anything healthy', despite the different occurrences of the highly polysemous word 
'healthy'. The utterance meaning we comprehend in individual instances are what we use as evidence when theorizing about linguistic meanings. Linguistic meanings are thus in some sense theoretical constructs.

These considerations point to a problem with O'Callaghan's argument, if construed as an argument against experiencing semantic properties. ${ }^{\mathrm{I}}$ The sounds associated with the words 'pole' and 'poll' are indeed identical yet the words mean different things. My reply: simply pronouncing these words is not a case of using the words. It is merely a case of pronouncing the sounds associated with two different lexical entries. Yet, as already argued, we cannot hear the meaning of sounds associated with lexical entries because the meanings of lexical entries are ineffable; they are not ordinarily accessible to consciousness. So, the simple argument from homophony does not work.

O'Callaghan preempts something like this objection but proceeds by arguing that the lack of difference in phenomenology persists even when we focus on particular uses of the words 'poll'/'pole'. He invites us to listen to utterances of 'Ernest used the pole to vault over the high bar', 'Last year Mac visited the southern pole of Earth', and 'Bubb won the greatest number of votes in our latest poll'. O'Callaghan maintains that even when uttered as part of a sentence, we will be unable to attend to anything audible in the three utterances of "poll/pole" that makes them different.

My reply: It seems, however, that the specific meanings of the homophones do make a difference to the phenomenology of the listening experiences. If the same sounds ('poll'/'pole') appeared in a foreign language, as in the case of an utterance of the Danish sentence 'Giv dukken til Poll', ${ }^{2}$ the experience of the word would be different. We would have no impression of experiencing a meaning. In fact, O'Callaghan's own explanation of the phenomenal contrast between listening to a known language and a foreign language, which we will revisit below, has exactly the same alleged problematic implication.

Having rejected that an auditory experience of meanings can explain the phenomenal contrast between listening to a known language and listening to a foreign language, O'Callaghan owes us a different explanation of the phenomenal contrast. His explanation turns on our familiarity with the sounds of a language. Learning a language, he argues, changes the temporal and qualitative features that speech sounds are experienced as having. When we learn

I This is not to say that O'Callaghan's intention in putting forth the argument was to establish that we don't perceive semantic properties but only that one might potentially use this sort of argument to attempt to show that we don't perceive semantic properties.

2 Here we can imagine that someone is simply named 'Poll', pronounced like the English word. The utterer would then be asking someone to give the doll to Poll. 
a language we become better at detecting the language-specific phonetic and phonological properties of the language, which alters how the sounds are experienced.

This explanation of differences in phenomenology between familiar and foreign languages faces several challenges, however. First, it cannot explain the feeling that there is an immediately perceptible difference between different "in-context" utterances containing different homophones (e.g., 'pole' and 'poll').

Second, two different languages can have exactly the same speech sounds but nonetheless have different meanings associated with those speech sounds (Brogaard, 20I6). Even though the speech sounds are the same, learning the language nonetheless changes the phenomenology of our overall experiences of utterances in the language. The most plausible explanation of this phenomenal contrast is a shift in the perception of what was said.

Third, the debate about whether one can hear the meaning of utterances carries over to written and figurative language, including braille and sign language. There is, arguably, a phenomenal difference between looking at or touching a message written in a known language and a message written in a foreign language. If we are immediately aware of the content of the message, then this could plausibly be taken to explain the difference in phenomenology. But if we merely see the configuration of the letters of the message and then go through a number of inferences to reach an interpretation, then a different explanation of the difference in phenomenology between seeing a message written in a known language versus a foreign language is called for. Changes in the temporal and qualitative features that speech sounds seem to have cannot explain the phenomenal difference in this case, and, as we will see below, it is questionable that learning a language can change the qualitative features that graphemes are experienced as having without our also having an auditory experience of what the message communicates.

\section{Empirical Evidence for the Perceptual View}

Before we turn to the skeptical argument against the possibility of knowledge of meaning, let me outline four pieces of empirical evidence in favor of the perceptual view of speech comprehension. The first piece of evidence for the view comes from the standard Stroop effect. The Stroop effect, in its classical form, is an effect found when attention-grabbing word meaning interferes with 
the naming of the ink the words are printed in. For example, if the word 'red' is printed in the ink color green, then it is harder to name the ink color than if it had been printed in red (or black). It typically takes longer to name the ink color when it does not match the word meaning. We are also more prone to mistakes when the ink color is contrary to the color depicted by the word. One possible explanation of this effect is that the meaning of the word captures our attention and thereby distracts us from the task we are supposed to carry out.

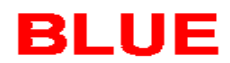

\section{PINK}

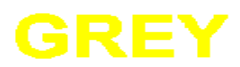

\section{TAN}

\section{GREEN}

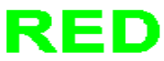

BLACK

WHITE

\section{YELLOW}

\section{ORANGE}

\section{PURPLE}

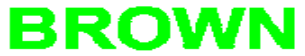

Fig. I: The word 'blue' is here displayed in the color red and the word 'green in the color 'blue', and so on. It takes longer for subjects to name the color of the ink when the word is printed in a color that differs from the color designated by the word than when it is printed in black or the same color as the color designated.

The standard explanation of this attentional bias is that the processing of meaning in the sensory cortex interferes bottom-up level with the intellectual naming task. The effect thus appears to indicate that the processing of meanings occur at the perceptual level, which points to the perceptual view of meaning comprehension.

A second piece of empirical evidence in favor of the perceptual view comes from a variation on a standard visual search paradigm. When shown an array of a meaningful word (the target) and meaningless variations on that word (the distractors), the meaningful word pops out and immediately grabs our attention (Fig. 2). Visual search paradigms are supposed to be a test of whether experience requires focused attention. If experience of meanings does not require focused attention, then the target item should capture attention, which would lead to highly efficient (fast and accurate) identification of the target. If, on the other hand, experience of meaning does require focal attention, then the target word should not capture attention and the identification process should be inefficient (slower and less accurate). Perceptual features must be processed 
early enough in the visual system for them to attract attention and lead to segregation (Beck, 1966; Treisman, 1982). So the appearance that experiences of the meanings of words among pseudowords can lead to pop-out and segregation indicates that these experiences occur at an early level of sensory processing.

$\begin{array}{lll}\text { phleteone } & \text { enlehpoet } & \text { telephone } \\ \text { ohleetenp } & \text { thepeone } & \text { eelehonpt } \\ \text { honetelep } & \text { letenepho } & \text { eeetlponh }\end{array}$

Fig. 2: The word 'telephone' pops out in an area of words and pseudowords. This test indicates that we perceive meaningfulness rather than meaning as such.

It should be noted that this particular test is not aiming at showing directly that we perceive word meanings but rather whether the property of being meaningful is presented in perceptual experience. However, there is good reason to think that the ability to perceptually determine meaningfulness normally depends on being able to perceptually determine particular meanings. For example, in order to experience 'telephone' as meaningful, you must have perceptual access to the meaning of 'telephone'. If this is so, however, the popout effect indicates that individual meanings normally are also presented in low-level perception.

A third empirical test that meanings are presented in experience turns on the notion of evidence insensitivity. We know from the case of visual experience of low-level features that these experiences are evidence insensitive. For instance, in the Müller-Lyer Illusion, even after being told that the line segments have the same length, they seem to have the different lengths (Fig. 3).
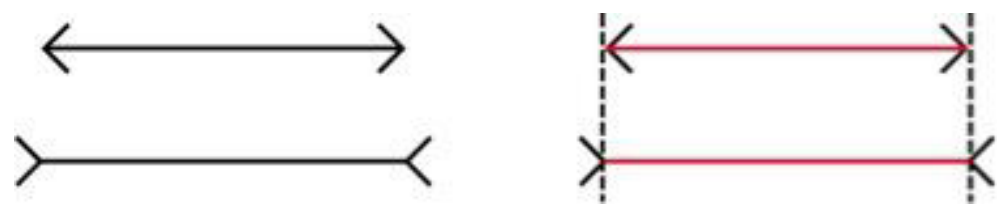

Fig. 3: The Müller-Lyer Illusion. Even when you learn that the line segments on the left have the same length, they continue to appear as if they have different length. This indicates that low-level experience is evidence insensitive.

Low-level perceptual experiences are thus normally insensitive to counterevidence. Experiences of utterances are likewise evidence insensitive. Consider (from Longworth, 2008): 
(Ia) More people have been to France than I have.

(Ib) The shopkeepers were unsatisfied by midnight.

(Ic) That's the first time that anyone sang to me like that before.

The sentences in (I) are not grammatically meaningful. Even so, the appearance that an utterance of a sentence like 'More people have been to France than I have' is meaningful may persist even after we realize that it is, in fact, incomprehensible, which means that experiences of the meaningfulness of these sentences are evidence insensitive. This indicates that the property of being grammatically meaningful is presented in experiences of speech. Now, saying this is different from saying that particular word meanings are presented in the perceptual exposure to utterances, but to the extent that a grasp of meaningfulness depends on a grasp of individual meanings, it does suggest that particular meanings may be presented in experience.

A fourth piece of empirical evidence in favor of the perceptual view comes from cases of semantic priming. In the standard priming task, study participants see a prime word (e.g., 'nurse') presented on a computer screen. They then see a target word (e.g., 'doctor') presented on the screen. When asked to respond to a target word,, subjects respond faster and more accurately to the target if the target is semantically, pragmatically and/or associatively related to the prime (as in 'doctor' versus 'forest') (see e.g. Neely \& Kahan 200I). In a variation on the standard paradigm, a mask is presented briefly after the prime is presented. This ensures that the prime is processed below the level of conscious awareness. Even in masked priming experiments, the volunteers' responses to the target words that are semantically, pragmatically and/or associatively related to the prime tends to be faster and more accurate than if the target word is not related in this way (Fig. 4).

A traditional explanation of semantic priming is that the prime activates representational memory neurons, which in turn facilitates the processing of the target word (see e.g., Collins \& Loftus, 1975). This mechanism has received additional backing after the reinstatement theory of memory gained traction (Eichenbaum, 2004; Serences et al., 2009; Rissman and Wagner, 2012). According to the latter theory of memory, memory retrieval consists in a reinstatement of activity in the neural circuits that were initially involved in processing the external stimulus. For example, when retrieving a visual memory, activity is reinstated in the visual cortex, whereas an activity is reinstated in the auditory cortex and other neighboring areas when retrieving an auditory memory. Hearing a recognizable word likely reinstates activity in the Wernicke's area, which is located in the superior temporal gyrus right next to the 
auditory cortex. Wernicke's area is involved in utterance comprehension and understanding of written language. As in all cases of sensory recognition, sensory brain regions outside the primary sensory areas are invoked in the process. For example, seeing a blue dot will activate the primary visual cortex as well as the color areas in the visual cortex (or slightly outside of the visual cortex). Likewise, restatement of activity in the areas originally used to comprehend a given prime word likely facilitates processing of semantically, pragmatically or associatively related words whose encoding overlaps with the encoding of the prime. This can explain the faster and more accurate responses to target words that are semantically, pragmatically or associatively related to their primes. It also points to the perceptual view of speech comprehension as the most compelling theory of utterance comprehension.

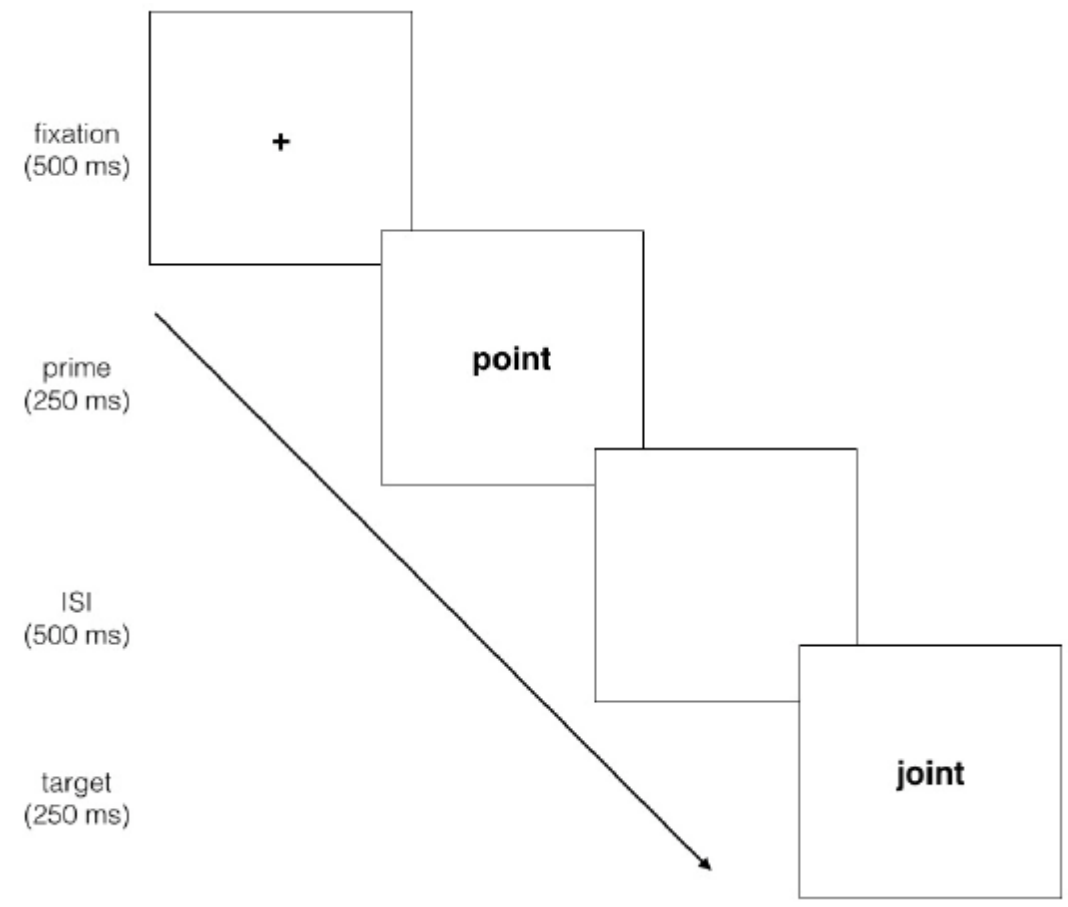

Fig. 4: Standard masked priming. Subjects are exposed briefly to a word. The word is then covered by a mask. Finally, the target word is presented to them. Subjects' respond more quickly when the prime is semantically related to the target word. For example, in this case the target and the prime word rhyme, which speeds up the recognition of the target word. 


\section{Immediate Justification of Belief}

If utterance comprehension is sensory in nature, as the empirical evidence indicates, then the question is whether experiences of what is said can justify our beliefs about what was said without drawing on background information. This latter view - also known as 'phenomenal dogmatism' - has had its supporters and opponents (see e.g. Pryor, 2000; Huemer, 200I; Huemer, 2007; Tucker, 20I0; Brogaard, 2013; Brogaard, 2016; Chudnoff, 20I4 for arguments in favor and Markie, 2005; Siegel 2012 for arguments against) According to the phenomenal dogmatist, at least some perceptual appearances provide immediate and full justification for belief in the absence of defeaters. But not all appearances are of the kind that can provide immediate and full justification for belief. Consider the following illustration (Fig. 5):

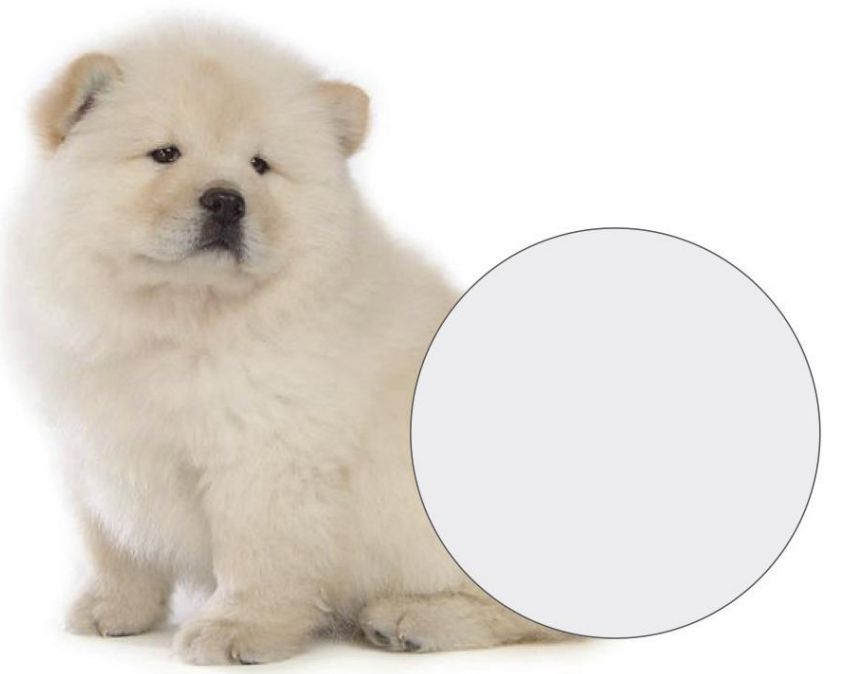

Fig.5: The dog is partially occluded. The truth-conditions for your appearance of the dog include both the proposition that that is a dog and awareness of the truth-maker for that proposition but it does not include awareness of the dog's tail. So, while your experience of the dog has presentational phenomenology, your experience that the occluded parts are parts of a dog does not.

If it perceptually appears to me that what is hidden behind the occlusion is part of a dog, and I come to believe it, this appearance does not by itself justify my belief. At best, it confers justification on my belief together with background assumptions about dogs and tails.

This raises the question: what distinguishes those appearances that have the 
features required in order to confer immediate justification on belief from those that do not?

Elijah Chudnoff has argued that only appearances with a presentational phenomenology confer immediate justification upon belief, that is, phenomenal dogmatism should be restricted to those cases in which appearances have a presentational character, such as the appearance of the whole dog 'popping' out in front of your eyes (Chudnoff 20I4; cf. Chudnoff 2013, p. 90, p. 94; Chudnoff, 2016; Chudnoff forthcoming).

To a first approximation, experiences have presentational character only when their accuracy conditions include both $p$ and awareness of a truthmaker for $p^{\prime}$ (Chudnoff, Forthcoming b). Returning to the occluded dog, your visual experience of the dog makes you aware of the proposition that the dog is sitting as well as the truthmaker for that proposition, but it does not make you aware of a truthmaker for the proposition that the dog has a short tail, a long tail or no tail or that the tail continues in one direction rather than another. On this view, the content of an experience of the sitting dog is not simply the dog is sitting but something like: that dog is sitting, and it seems that I am aware of a truthmaker for the proposition that that dog is sitting. Experiences of occluded parts of objects have a different content. For example, an experience of the occluded part of the dog being part of a dog might have the content: that part is part of that dog but I am not aware of a truthmaker for the proposition that that part is part of that dog.

Chudnoff's proposal, however, runs into trouble with respect to experiences of what is said by sound sequences. The trouble is that auditory sequences give rise to the illusion of auditorily experienced meanings that appear to be evidence insensitive in just the same way as lower-level visual illusions (cf. Longworth, 2008). Yet it is quite implausible that we are aware of any apparent truth makers for the content of the experience of meanings. For example, we are not directly aware of the speaker's intentions.

A better candidate to be what distinguishes those experiences that confer justification on belief without background assumptions from those that do not is felt evidence sensitivity. Felt evidence sensitivity differs from evidence sensitivity in that the latter is a dispositional property, whereas the former is a featur of the phenomenology of experience. When looking at the Muller-Lyer illusion, for example, it feels to us that no amount of evidence could change how we feel about the perceived length of the lines. Likewise, in speech comprehension, when faced with an utterance of a sentence of the type in I(a)-(c), we have a feeling that no knowledge of grammaticality could undermine the appearance of meaningfulness. 
Here is another example: suppose a colleague of yours is known for being critical of virtually every department colloquium talk. As you enter the wine and cheese reception following the talk, it seems to you that your colleague is saying 'the speaker misunderstood my question' when in reality he uttered the sounds 'the speaker was really good in response to my question'. If you are told that your colleague said the latter but not the former, this may not change the appearance that the speaker said the former. Your experience represents the apparent meaning of the utterance as resistant to counterevidence. You heard what you heard after all. You feel that evidence simply could not possibly refute the appearance itself but only your belief. In such cases, experiences of meaning can have the same evidence sensitivity or felt evidence sensitivity as low-level experiences. It is this felt resistance to counterexamples that some experiences have that makes them good candidates to be an immediate justifier of belief. This is because felt evidence sensitivity typically tracks the truth. When we feel certain about what we appear to see or hear, our experiences are more likely than not to be veridical, at least in normal non-demon plagued worlds.

\section{The Skeptical Argument Against Knowledge of Meaning}

This finally leads us to a significant virtue of the perceptual view. One major challenge to the inferential view of utterance comprehension is that it lends itself to the view that we cannot come to know the meanings of utterances, or the even more radical view that meanings themselves are indeterminate. As Dean Pettit (20IO) has argued, the problem arises owing to the epistemic implications of the inferential view for language acquisition. Acquiring a correct belief set about the syntax and semantics of the language doesn't suffice for comprehending what speakers say; those beliefs would also need to be justified. This is the idea underlying Davidson's (1973) thought experiment of the radical interpreter who is faced with the task of interpreting a completely foreign language. The theorist interprets the language on the basis of the available evidence, which are observations of the linguistic and non-linguistic behavior of the speakers. The problem is that the available evidence underdetermines facts about meaning, since that evidence is compatible with rival hypotheses about the meaning of the utterances. This leads Davidson to argue not merely that we cannot come to know the meaning of the utterances we hear but also that there are no determinate facts about meaning, because facts about meaning cannot outstrip the ability of all the speakers of a language. 
This sort of skepticism does not follow from the perceptual view of language comprehension when combined with the thesis that experience can confer immediate justification upon belief, because on the latter view, our experiences of what is said immediately justify our beliefs about what is said without any reliance on further belief or theorizing, at least in the absence of defeaters. So, in the absence of defeaters, our beliefs about the meanings of utterances are justified.

When combined with the epistemic hypothesis, the perceptual view thus has the advantage over the inferential view insofar as it can block a potential route to a radical view of language comprehension (cf. McDowell, 1978; McDowell, 198I). ${ }^{3}$ The problem with this solution to the skeptical problem is that it requires that one accepts the epistemic component of the view. But, as we have seen, there may be reason to reject this part of the perceptual view. There is, however, a different route to blocking the skeptical argument that does not rely on the epistemic component.

The idea that we can come to know what speakers say by listening to them and otherwise observing them seems to be doomed if meanings are private. If, however, meanings are public, then they ought to be discoverable like other public objects. Perceivable objects arguably are public. So, if meanings are perceivable, then they are public and arguably are discoverable. The argument can presented more succinctly as follows:

(I) Are meanings private or public? If they are private, how do we grasp them?

(2) If they are perceivable, then they are public just like other perceivable objects.

(3) Hence, there is no particular problem of language comprehension, even if meanings originate in "private" mental states.

This argument is consistent with the thought that experiences of what is said do not by themselves confer justification on belief. Suppose you tell me 'I bought a new coat'. Suppose further that I perceive you as having said that you bought a new goat but despite knowing that you went to the mall and hate goats I irrationally form the belief that you said that you bought a new goat. An exponent of the view that experiences of utterance meanings can confer immediate justification upon belief can say that your irrational belief is

3 There are, of course, other ways to block the Davidsonian line of argument. So, this line of argument should not be taken to be the main reason to adopt the perceptual view of language comprehension. 
prima facie justified directly on the basis of the perceived meaning but that my background knowledge that you just went to the mall and hate goats serve as an undercutting defeater of the justification for my belief, that is, the defeater severs the justificatory relation between my experience and my belief without severing the basing relation between the two.

An opponent of the view that experiences of utterance meanings can confer immediate justification upon belief, however, can also avoid skepticism about knowledge of meanings and yet maintain that you do not have justification for your belief about what was said because your background beliefs together with your experience do not jointly provide full justification. ${ }^{4}$ My experience of what was said, the opponent might say, confers partial justification upon my belief. But the background information does not provide the remaining part of the justification needed in order for the belief to become fully justified. This is so because the belief that you bought a new goat is inconsistent with my knowledge that you hate goats but love coats and just went to the mall. Owing to this inconsistency, I fail to have knowledge of what was said. In other cases, however, my experience of what was said together with my background knowledge can jointly justify my belief about what was said (e.g, in a case where it appears to me that you said that you just bought a new coat).

Regardless of whether you accept the epistemic component of the perceptual view, then, the defender of the perceptual view can thus ward off the skeptic about knowledge of meaning.

\section{Conclusion}

Empirical evidence points to utterance comprehension being a sensory phenomenon. If indeed utterance comprehension is a sensory phenomenon, then we can combine the view with the view that sensory experiences confers immediate and full justification upon belief (in the absence of defeaters). This seems to provide the foundation for a compelling reply to Davidson. There is, however also another way to reply to this type of argument that does not require buying into the epistemic hypothesis. On this view, if utterance comprehen-

4 The background information here is not simply that you went to the mall and hate goats but rather some principle to the effect that if you hate goats, you are unlikely to sincerely convey the information to me that you just bought a goat. It is worth pointing out that no inferential process is needed in order for your background beliefs and your experience to jointly justify your belief in those cases where your belief is indeed justified. 
sion is perceptual, the meanings conveyed - or what is said - must be public. But if meanings are public, then Davidson's argument is unsound, as it depends on the assumption that meanings are private. ${ }^{5}$

\section{References}

Bayne, T. (2009). "Perception and the Reach of Phenomenal Content," The Philosophical Quarterly 59, 236, 385-404.

Balcerak-Jackson, B. (manuscript) Against the Perceptual Model of Utterance Comprehension

Beck, J. (1966). Effect of orientation and of shape similarity on perceptual grouping. Perception and Psychophysics, I, 300-302.

Bergmann, M. (2013). "Phenomenal Conservatism and the Dilemma for Internalism." In Seemings and Justification: New Essays on Dogmatism and Phenomenal Conservatism, C. Tucker (ed.), Oxford: Oxford University Press: 154-I80.

Brogaard, B. (2013) „Phenomenal Seemings and Sensible Dogmatism“, In C. Tucker, ed. Seemings and Justification: New Essays on Dogmatism and Phenomenal Conservatism, New York: Oxford University Press, 2013, 270-289.

Brogaard, B. (In press, a). "Perceptual Appearances of Personality", Philosophical Topics.

Brogaard, B. (2016). "In Defense of Hearing Meanings", Synthese pp I-17 First online: o6 August 2016.

Brogaard, B. and Chomanski, B. (20I5) „Cognitive Penetrability and High-Level Properties in Perception: Unrelated Phenomena?“, Pacific Philosophical Quarterly 96: 469-486.

Brogaard, B. and Gatzia, DE. (20I5). „Is the Auditory System Cognitively Penetrable?“ Front Psychol.; 6: II66. DOI: I0.3389/fpsyg.2015.01166

Chandrasekaran, B., Skoe, E., Kraus, N. (2013) "An Integrative Model of Subcortical Auditory Plasticity." Brain Topography. doi: Io.I007/sio548-013-0323-9

Chalmers, DJ. The Representational Character of Experience, in 2004. 'The Representational Character of Experience', in B. Leiter (ed.), The Future for Philosophy, Oxford: Oxford University Press.

Chase, W. G., \& Simon, H. A. (1973a). "The Mind's Eye in Chess.” In W. G. Chase (Ed.), Visual information processing (pp. 215-28I). New York: Academic Press.

Chase, W. G., \& Simon, H. A. (1973b). "Perception in Chess," Cognitive Psychology, $4,55-8$ I.

Christianson, K, Luke SG and Ferreira F (20I0). "Effects on Plausibility on Structural Priming," Journal of Experimental Psychology: Learning, Memory, and Cognition 36,

5 I am grateful to Brendan Balcerak-Jackson, Ned Block, Anna Drożdżowicz, Casey O'Callaghan, Francois Recanati, Josh Weisberg and Wayne Wu for helpful discussion of these issues and to Elijah Chudnoff, Kathrin Glüer, Anandi Hattiangadi, Casey Landers, Luca Moretti, Peter Pagin, Tommaso Piazza, David Poston, Dag Westerståhl, and audiences at NYU, Stockholm and Houston for for helpful comments on a previous version of the paper. 


\section{$538-544$}

Chudnoff, E. (2013). Intuition, Oxford: Oxford University Press.

Chudnoff, E. (20I4). "Review of Tucker (eds.) Seemings and Justification," Notre Dame Philosophical Reviews. http://ndpr.nd.edu/news/48II8-seemings-and-justificationnew-essays-on-dogmatism-and-phenomenal-conservatism/

Chudnoff, E. (Forthcoming). "Intuition, Presentational Phenomenology, and Awareness of Abstract Objects", Florida Philosophical Review.

Chudnoff, E. (20I6). Moral perception: High level perception or low level intuition? In T. Breyer

592 \& C. Gutland (Eds.), Phenomenology of thinking. London: Routledge, 207-220.

Chudnoff, E. and DiDomenico, D. (2015). “The Epistemic Unity of Perception," Pacific Philosophical Quarterly, 96: 535-549

Collins, A.M., \& Loftus, E.F. (I975). A spreading activation theory of semantic processing. Psychological Review, 82, 407-428.

Conee, E. (2013). "Seeming Evidence." In Seemings and Justification: New Essays on Dogmatism and Phenomenal Conservatism, C. Tucker (ed.), Oxford: Oxford University Press: 52-70.

Davidson, D. (1973). "Radical Interpretation," Dialectica 27. Reprinted in Inquiries into Truth and Interpretation' (pp. I25-I40). Oxford: Clarendon Press, I984.

Eichenbaum H. (2004). The Hippocampus, Memory, and Place Cells: Is It Spatial Memory or a Memory Space?. Neuron 44(I):IO9-I2O.

Ferreira, F, Bailey KGD, Ferraro V (2002). "Good-Enough Representations in Language Comprehension.” Current Directions in Psychological Science II, II-I5.

Fodor, J. 1983. Modularity of Mind. Cambridge, MA: MIT Press.

Fricker, E. (2003). "Understanding and Knowledge of What is Said”. In A. Barber (ed.) Epistemology of Language, 325-366. London: Oxford University Press

Glezer LS, Kim J, Rule J, Jiang X, and Riesenhuber M (2015). "Adding Words to the Brain's Visual Dictionary: Novel Word Learning Selectively Sharpens Orthographic Representations in the VWFA", The Journal of Neuroscience 35(I2): 4965-4972.

Ghijsen, H. (2015). "Grounding Perceptual Dogmatism: What are Perceptual Seemings?" The Southern Journal of Philosophy 53 (2): 196-215.

Gilbert, C. D. and Li, W. (2013) "Top-Down Influences on Visual Processing." Nature Reviews: Neuroscience I4: 35I.

Gobet, F., \& Simon, H. A. (1996).”Templates in Chess Memory: A Mechanism for Recalling Several Boards," Cognitive Psychology, 3I, I-40.

Gobet, F., \& Simon, H. A. (2000). "Five Seconds or Sixty? Presentation Time in Expert Memory," Cognitive Science, 24, 65I-682.

Gordon, IE (2004) Theories of Visual Perception, 3rd ed, Hove, UK: Psychology Press.

Huemer, M. (200I). Skepticism and the Veil of Perception. Lanham, MD: Rowman and Littlefield.

Huemer, M. (2007). "Compassionate Phenomenal Conservatism.” Philosophy and Phenomenological Research 74: 30-55.

Longworth, G. (2008). "Linguistic Understanding and Knowledge," Nous 42, I: 50-79.

Lotto, A. \& Holt, L. L. (20II) "Psychology of auditory perception." Wiley Interdisciplinary Reviews: Cognitive Science 2(5): 479-489.

Lyons, J. (2015). "Seemings and Justification." Analysis Reviews 75 (I): I53-I64. 
Markie, P. (2005). "The mystery of direct perceptual justification", Philosophical Studies I26: $347-373$.

McDowell, J. (1978) "On 'The Reality of the Past", in C. Hookway and P. Pettit, eds., Action and Interpretation, Cambridge, Cambridge University Press: 127-44

McDowell, J. (198I) "Anti-Realism and the Epistemology of Understanding", in Herman Parret and Jacques Bouveresse, eds., Meaning and Understanding (De Gruyter, Berlin and New York, 198I): 225-48

McLaughlin, B, Rossman, T; McLeod, B. (1983) "Second Language Learning: An Information-Processing Perspective", Language Learning, 06/1983, 33, 2, 33, Issue 2: $135-158$.

Neely, J. H., \& Kahan, T. A. (200I). Is semantic activation automatic? A critical reevaluation. In H. L. Roediger, J. S. Nairne, \& A. M. Surprenant (Eds.), The nature of remembering: Essays in honor of Robert G. Crowder (pp. 69-93). Washington, D. C.: American Psychological Association.

O'Callaghan, C. (20II). "Against Hearing Meanings," The Philosophical Quarterly, IO/2OII, 6I, 245: 783-807.

Pettit, D. (2010). "On the Epistemology and Psychology of Speech Comprehension", The Baltic International Yearbook of Cognition, Logic and Communication October 20Io Volume 5: Meaning, Understanding and Knowledge pages I-43

Politzer, G. \& Bonnefon, J.-F. (2006). "Two Varieties of Conditionals and Two Kinds of Defeaters Help Reveal Two Fundamental Types of Reasoning," Mind and Language 2I (4):484-503.

Pollock, J. (1986). Contemporary Theories of Knowledge. Savage, MD: Rowman and Littlefield.

Pollock (1987). „Defeasible Reasons“, Cognitive Science II, 4, 48I-5I8.

Pryor, J. (2000) The Skeptic and the Dogmatist, Nous 34:4: 517-549

Pylyshyn, Zenon (1999) "Is Vision Continuous with Cognition? The Case for Cognitive Impenetrability of Visual Perception." Behavioral and Brain Sciences 22: 34I-423.

Recanati, F. (2004). Literal Meaning, Cambridge: Cambridge University Press.

Reiland, I. (2015a). "On Experiencing Meanings", The Southern Journal of Philosophy $53,4: 48 \mathrm{I}-492$.

Reiland, I. (20I5b). "Experience, Seemings, and Evidence." Pacific Philosophical Quarterly.

Rissman J, Wagner AD. (20I2). Distributed Representations in Memory: Insights from Functional Brain Imaging. Annual Review of Psychology 63:IOI-I28.

Serences JT, Ester EF, Vogel EK, and Awh E. (2009). Stimulus-Specific Delay Activity in Human Primary Visual Cortex. Psychol Sci. 20(2):207-2I4.

Siegel, S. (2005). "Which properties are represented in perception?" In T. Szabo Gendler \& J. Hawthorne (Eds.), Perceptual experience. Oxford: Oxford University Press, $48 \mathrm{I}-503$.

Siegel, S. (2012) "Cognitive Penetrability and Perceptual Justification." Noûs 46(2): 2OI-222.

Stanley, J. (2005). "Hornsby on the Phenomenology of Speech". The Aristotelian Society Supplementary Volume 79: I3I-46.

Suga, N., Xiao, Z., Ma, X., Ji, W. (2002) "Plasticity and Corticofugal Modulation for 
Hearing in Adult Animals." Neuron 36(I):9-18.

Swets, B, Desmet T, Clifton C jr. and Ferreira F (2008). "Underspecification of Syntactic Ambiguities: Evidence from Self-Paced Reading," Memory \& Cognition 36: 20I-2I6

Treisman, A. (1982). Perceptual grouping and attention in visual search for features and for objects. Journal of Experimental Psychology: Human Perception and Performance, 8(2), I94-2I4.

Tucker, C. (2010). "Why Open-Minded People Should Endorse Dogmatism." Philosophical Perspectives 24: 529-545. 